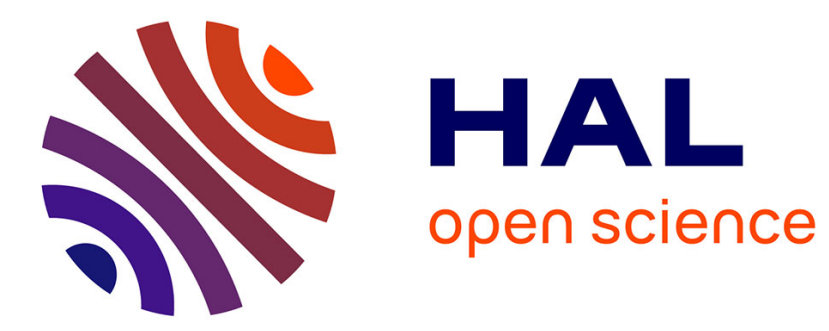

\title{
Business Process Simulation for the Design of Sustainable Product Service Systems (PSS)
}

Alice Rondini, Fabiana Tornese, Maria Grazia Gnoni, Giuditta Pezzotta, Roberto Pinto

\section{To cite this version:}

Alice Rondini, Fabiana Tornese, Maria Grazia Gnoni, Giuditta Pezzotta, Roberto Pinto. Business Process Simulation for the Design of Sustainable Product Service Systems (PSS). IFIP International Conference on Advances in Production Management Systems (APMS), Sep 2015, Tokyo, Japan. pp.646-653, 10.1007/978-3-319-22759-7_74 . hal-01431155

\section{HAL Id: hal-01431155 \\ https://hal.inria.fr/hal-01431155}

Submitted on 10 Jan 2017

HAL is a multi-disciplinary open access archive for the deposit and dissemination of scientific research documents, whether they are published or not. The documents may come from teaching and research institutions in France or abroad, or from public or private research centers.
L'archive ouverte pluridisciplinaire HAL, est destinée au dépôt et à la diffusion de documents scientifiques de niveau recherche, publiés ou non, émanant des établissements d'enseignement et de recherche français ou étrangers, des laboratoires publics ou privés.

\section{(c)(1)}

Distributed under a Creative Commons Attribution| 4.0 International License 


\title{
Business process simulation for the design of sustainable Product Service Systems (PSS)
}

\author{
Alice Rondini*, Fabiana Tornese**, Maria Grazia Gnoni**, Giuditta Pezzotta*, \\ Roberto Pinto* \\ *CELS - Dept. of Management, Information and Production Engineering - University of \\ Bergamo, viale Marconi 5, 24044 Dalmine (BG) - Italy \{alice.rondini, \\ giuditta.pezzotta, roberto.pinto\} @unibg.it \\ ** Department of Innovation Engineering - University of Salento, via per Monteroni, 73100, \\ Lecce-Italy ffabiana.tornese, mariagrazia.gnoni\}@unisalento.it
}

\begin{abstract}
Nowadays, a lot of manufacturing companies are shifting their value proposition from a product-centric perspective to sustainable Product-ServiceSystems (PSS). This transition allows companies to improve the customization of their offer and to contribute to the reduction of material flow and consumption; nonetheless, it poses some new challenges in terms of mindset and organization. In particular, the analysis of the literature about PSS shows that there is still a gap concerning the evaluation and the monitoring of new or reengineered PSS provision processes using business process simulation. Few examples of simulation in PSS field can be found, and multidimensional models considering customer perspective and environmental sustainability beyond the economic driver are not yet available. Thus, the purpose of this paper is to compare different simulation paradigms and to define the most suitable to support the engineering phase of a sustainable, customer-oriented PSS. Two possible alternatives were identified and discussed through a test-case.
\end{abstract}

Keywords: PSS. Customer. Sustainability. Simulation. Hybrid modelling

\section{$1 \quad$ Introduction}

Facing the difficult economic juncture, an increasing number of companies has been enlarging its value proposition starting to provide services in addition to their products, moving from a product-centric perspective towards the provision of sustainable Product-Service Systems (PSSs). This is contributing, from one side, to increase their revenues and customer satisfaction and, from the other side, to a dematerialization of their offering [1]. In particular, different are the advantages and the benefits achieved with the introduction of a PSS: (i) differentiation from competitors, (ii) customers lockin and (iii) competitors lock-out thank to the provision and selling of a unique solution [2]. Nevertheless, the shift to the PSS paradigm also poses some critical challenges to companies, as they are required to review the entire organization [2]. Furthermore, failing to manage this mindset shift can lead to limited payoffs and unsuitable revenues, thus originating the so-called "service paradox" [3]. This is the reason why Service Engineering (SE) [4], a relatively new research field, has been developed to adapt existing engineering know-how to services. It is not a completely mature discipline, 
and a common standard to deal with PSS and services is still missing [5]. Within this context, many authors $[6,7,8]$ defined possible design methodologies for PSS but none of the existing provide suggestions to i) manage the dynamics involved in a PSS (e.g. customer interaction or participation in the provision process; moving human resources and high variability in customer behaviour), ii) monitor and implement a PSS, and iii) manage the customer and company co-creation process. Therefore, considering these issues, the main goal of the paper is to answer to the following research questions (RQ):

1. What are the main KPIs of a PSS delivery process that should be evaluated to guarantee high customer value and to make it sustainable in the long term?

2. How do simulation paradigms (DES - Discrete Event Simulation, SD System Dynamics, ABM - Agent-Based Modelling, and Hybrid Modelling) allow gathering and managing the dynamics involved in a PSS?

3. How is it possible to integrate the environmental sustainability and customer satisfaction performances into a PSS simulated process?

On this basis, this study is based on the following four steps:

1. Identification of the main KPIs that should be monitored in a PSS delivery process;

2. Literature analysis of the state of the art in simulation modelling for sustainable PSS;

3. Identification of the existing simulation paradigms allowing sustainable PSS delivery process measurement;

4. Adoption and comparison of the simulation paradigms identified in a test-case.

The remaining part of the paper is structured as follows: section 2 describes the main KPIs to be considered in a PSS. Section 3 presents a brief literature review about simulation and environmental sustainability in PSS, whereas section 4 provides an overview of the test case together with considerations about the two different approaches. Section 5 presents the conclusions and possible further development directions.

\section{Identification of the main KPIs to be monitored in a PSS}

Literature analysis provides a useful overview to define the main performance that should be evaluated in a PSS delivery process. In particular, the co-creation process between the customer and the company is a leading concept to understand how the value is created in a PSS. Adopting the Service-Dominant logic, the roles of producers and consumers are not distinct, meaning that value is always co-created, jointly and reciprocally, in interactions among providers and beneficiaries through the integration of resources and application of competences [9]. From this point of view, both the customer (in terms of satisfaction) and the company (in terms of profitability and efficiency) perspectives might be taken into account. Moreover, one of the main elements emerged from the literature review is that, among the main advantages of a PSS, sustainability is becoming more and more relevant [10]. For this reason, it has been taken into account as well in our study.

To summarize and answer the RQ1, we consequently defined three main dimensions for the evaluation of a PSS delivery process: (i) process efficiency, (ii) customers' satisfaction, and (iii) environmental sustainability. 
To measure and monitor these dimensions, we tried to adapt and translate existing product-based knowledge into the service field. Among the existing tools largely used in traditional manufacturing industry to tackle the dynamics and to monitor the process , simulation is the most well-known, but its application to the PSS field is still largely unexplored [11]. In particular since "the interaction of people with processes and technology results in an infinite number of possible scenarios and outcomes that are not possible to predict and evaluate using widely popular static process modelling methods" [12], simulation has been selected. In this paper we will define simulation as "the process of designing a model of a real system and conducting experiments with this model for the purpose of understanding the behavior of the system and/or evaluating various strategies for the operation of the system" [13].

\section{State of the art about simulation modelling for sustainable PSS delivery process}

Concerning the adoption of simulation in the SE context, we have been looking for examples of simulation frameworks including both customers' involvement in the PSS delivery process and the environmental advantages carried out by the introduction of a PSS offering. No framework seems to provide a broad perspective considering these two dimensions as part of everyday business, but some studies actually deal with one or the other.

There are three main simulation paradigms widely used to model manufacturing systems: Discrete Event Simulation (DES), System Dynamics (SD) and Agent-Based Modelling (ABM). SD can easily represent flows and cause-effect relations in a system at a strategic level, starting from the consideration that the behavior of a system is strongly dependent on its structure. DES is process-centric and focuses more on the tactical/operational dimension level; it is, based on entity flows, resource sharing and sequences of activities. On the other hand, ABM is more effective in the modelling of individuals' behavior, through a bottom-up approach in which agents have their own rules and become active elements of the model [14]. All of them cannot be immediately adopted into the PSS field and literature highlights that the underpinning reasons must be sought in some key features of a PSS that are difficult to simulate, such as the presence of human beings whose behavior cannot be easily translated into an equation [15], the difficulty to define specific set of resources to allocate to service activities [16] and the still undefined concept of PSS productivity [17]. Nevertheless, there are few examples of the adoption of simulation modelling paradigms for both the assessment of (i) PSS sustainability and (ii) PSS customer and company's performance.

Regarding the evaluation of sustainability, there are two noteworthy examples. Lee et al. [18] show the application of SD to a PSS whereas [19] try to put together economic, social and environmental sustainability through a decision support system based on ABM.

Considering the company and the customer performance perspectives, there are only few studies. One of them is focused on the possible application of life cycle simulation to PSS [20] and another is an application of SD to the analysis of the impact of PSS in a manufacturing company [21]. Moreover, we found a single application of DES in services, specifically focused on efficiency in social services [22]. Only one approach 
has been specifically developed to analyze the performance of a PSS [23]. In addition, some interesting applications of ABM to PSS development focusing on customer's satisfaction have been found [14], [24].

Next to the three "pure" simulation paradigms presented, hybrid modelling grew out of the need to combine the advantages of two or more of these approaches, integrating in one model specific features from the different techniques. This allows attaining a higher flexibility and working at different levels of abstraction, exploiting at the same time the strengths of each method [25]. For these reasons, the opportunity to use a hybrid model has been considered as a possible way to better deal with the complexity and the dynamics of a PSS.

As a first conclusion, we can state that some attempts to evaluate sustainability or customer satisfaction in a PSS through a simulation approach already exist, meaning that simulation can help to gather the dynamics of a PSS. This provides an answer to RQ2, but still leaves a gap in the performance analysis because none of them considers all the three KPIs identified from a multidimensional perspective. On this base, to answer RQ3 we choose to analyze the system through two modelling solutions: a DES model, focusing more on the delivery process and activities of which the PSS is made up and a hybrid model, taking advantage of the specific features of both DES-ABM, in which customers are modelled through the ABM approach. This gives more centrality to their interaction with the PSS provider.

\section{Test case}

In order to better evaluate the potentiality of the identified approaches, we applied DES and ABM to a real case from the automotive sector where the service market can be four or five times larger than the market for products, and where nowadays there is a strong commitment to environmental sustainability. We decided to use a truck standard maintenance process as a test case, due to the extensive experience of some of the authors in that area. The process works as follows: first, the customer arrives at the workshop with his truck and is received by a receptionist. Then, the workshop foreman performs an initial diagnosis, provides a general quotation for the estimated services, and schedules the intervention. At its turn, the truck is exposed to three different maintenance activities and, if no additional problems arise, it is checked out and brought back to customer. If, instead, unplanned problems arise, or the final check does not show a proper condition, another maintenance activity is carried out. As in reality, there are two types of customers: (i) customer with a single truck and (ii) customers with a truck fleet. Of course, at the scheduling, the customer with a fleet available would bear better a long waiting time than the customer with only one truck that may eventually decide to leave the system before being serviced. For the sake of simplicity, at this point of the analysis the truck utilization of both the two customers would not be considered. As hinted before, the automotive sector is characterized by high pressure from the environmental point of view. In relation to a maintenance process, there are different elements that can be taken into account; however, for the case presented in this study, only the use of refurbished spare parts has been considered: that is, the customer has the possibility to choose between new or refurbished spare parts both for the scheduled maintenance and for the unplanned problems solving phase. 
All the data related to the number of maintenance requests, the activities duration, the customer willingness to wait, the number of utilized spare parts and the resources employed have been taken from the company database and direct observations. Data related to sustainability have been inferred from literature (e.g., the percentage related to the adoption of refurbished spare parts [26]).

For what concerns the measurement of the main KPIs, we decided to use resources utilization coefficients (workers and work spaces) to give a proxy for the economic efficiency, while the total waiting time, the total service time and the percentage of customers leaving the system before being served (they do not want to wait too much time in queue) help to understand what is the service level perceived by the customer. Finally, the environmental gain due to the customer's choice of buying refurbished spare parts is modelled through the indicator of $\mathrm{CO} 2$ avoided emissions. In this case, a general reference value has been gathered from a study about remanufactured diesel engines [27], not considering the variety of spare parts that can be substituted in a truck maintenance process. This approximation can be justified observing that the focus of the analysis is not the real case, but the application of the simulation to evaluate KPIs in a PSS.

Two models have been built: a DES model built using Arena Rockwell simulation and a hybrid DES-ABM model built using Anylogic. Input data, not reported in this paper, were the same in both the two models. In Table 1, the results (mean values) of the simulation considering the three main dimensions identified are reported considering both DES and hybrid models. The total simulation time is equal to six months; the service company is open five days a week, eight hours per day. The results obtained are aligned with the as-is real data.

The test case performed represents just an initial step in defining an integrated PSS simulation approach. In this sense, the work performed helped to shed light on the possible use of business process simulation in assessing PSS performance, confirming that this tool can reveal useful to manage PSS dynamism. In this sense, both the two approaches suggested (DES and Hybrid model) provide an answer to RQ2 having an acceptable fit with reality. Moreover, both are capable to measure the three main areas of performance indicated. This last point, that answers RQ3, is demonstrated by the data shown in Table 1 with the results related to company, customers and sustainability dimensions. Results from the two approaches are almost similar, but there is a discrepancy in the percentage of customer leaving the system. This is caused by one of the main problems emerged in DES with Arena software that has some limitations in defining the schedule arrival of trucks. The initial distribution reveals less random than expected; for this reason, the number of truck waiting is higher and consequently a higher percentage of customer leaves the system. This reason also explains the difference in the service time (from 1,8 to 1,4 days).

Table 1. Results of simulations

\begin{tabular}{llcc}
\hline Criteria & Parameter & DES & $\begin{array}{c}\text { Hybrid } \\
\text { model }\end{array}$ \\
\hline & $\mathrm{N}^{\circ}$ customers entering the system & 597 & 611 \\
\hline $\mathrm{N}^{\circ}$ customers served & 513 & 568 \\
\hline & Mechanics utilization & $44 \%$ & $44 \%$ \\
\hline
\end{tabular}




\begin{tabular}{llll}
\cline { 1 - 1 } $\begin{array}{llll}\text { Economic } \\
\text { efficiency }\end{array}$ & Workshop foreman utilization & $33 \%$ & $35 \%$ \\
& Receptionist utilization & $39 \%$ & $40 \%$ \\
& Work space utilization & $95 \%$ & $89 \%$ \\
\hline Customer & Service time & 1,8 (days) & 1,4 (days) \\
satisfaction & Total waiting time per customer & 1,5 (days) & 1,2 (days) \\
& $\%$ of customers leaving the system & $15,0 \%$ & $6,5 \%$ \\
\hline Environmental & Avoided $\mathrm{CO}_{2}$ emissions & $7,7 \%$ & $7,2 \%$ \\
sustainability & & & \\
\hline
\end{tabular}

The less random distribution indeed causes higher queues in the initial part of the process where the customer cannot decide to leave the queue. Finally, the negligible difference in the number of entities entering the system can be influenced as well by this problem. Apart from this clear difference in the two approaches, the work performed for this study also highlights some advantages of hybrid technique with respect to DES. In particular, the use of ABM to model customers' behavior and preferences creates a considerable advantage in terms of model definition and use. This method allows for the definition of copious rules that agents have to follow and in this way facilitates the creation of the DES part that describes the process. The pure DES approach indeed can describe the customer rule for the simple test case, but it required additional technical expedients and work. Due to space constraint, data and other simulations results have been omitted. However, they are available - with the exception of those subject to non-disclosure agreement - upon request to the corresponding author.

Further analysis can encompass the adoption of the two approaches to describe a more complex PSS process. Through this, the advantages of the hybrid simulation paradigm would become clearer. The use of the approaches in more complex scenarios can be also a good starting point for the analysis of additional drivers to measure the three main KPIs identified (e.g. costs as a driver for efficiency, a qualitative evaluation of customer service, material consumption, energy utilization and waste reduction to evaluate environmental sustainability).

\section{$5 \quad$ Conclusions and further developments}

The study presented in this paper illustrates a possible integrated simulation approach to evaluate a PSS from multiple perspectives. First, a literature analysis has been performed to define a set of integrated and effective metrics for PSSs. In this still open research area, we decide to consider three main performance dimensions: i) customer satisfaction, ii) economic efficiency and iii) environmental sustainability (RQ1).

In the second stage, a literature analysis on simulation paradigms has been carried out showing that DES, ABM and SD have been rarely applied to design services and PSSs. The hybrid simulation paradigm is also still unexplored in PSS environment.

Two possible simulation approaches have been defined to test the different simulation approaches: the first one is based on DES paradigm, and the latter uses a hybrid model, which integrates advantages of DES and ABM paradigms. The two have been applied in a test case and evaluated through their ability to describe the customer 
and companies' complexity. The results show that both the models allowed the measurement of the performance of the three metrics defined (RQ2), but the hybrid model revealed more useful in defining PSS and customer interaction monitoring the three strategic perspectives (RQ3).

Further developments can regard the analysis of more complex test cases with the introduction of other variables and constraints, in order to investigate the potentialities of hybrid modelling for PSS more in depth.

\section{References}

1. UNEP. (2002). Product-Service Systems and sustainability, opportunities for sustainable solutions. UNEP.

2. Neely, A. (2008). Exploring the financial consequences of the servitization of manufacturing. Operations Management Research, 1(2).

3. Gebauer, H., Fleisch, E. and Friedli, T. (2005). Overcoming the service paradox in manufacturing companies. European Management Journal, 23(1), pp. 14-26.

4. Bullinger, HJ., Fahnrich, KP., Meiren, T. (2003). Service engineering-methodical development of new service products. International Journal production Economics, pp. 275287.

5. Cavalieri, S., Pezzotta, G. (2012). Product-Service Systems engineering: state of the art and research challenges. Computers in industry, 63(4), pp. 278-288.

6. Welp, E.G., Meier, H., Sadek, T. and Sadek, K. (2008). Modelling approach for the integrated development of industrial Product-Service Systems. The 41st CIRP Conference on Manufacturing Systems '08

7. Aurich, J., Fuchs, C. and Wagenknecht, C. (2006). Life cycle oriented design of technical Product-Service Systems. Journal of Cleaner Production, 14(17), pp. 1480-1494.

8. Shimomura, Y., Hara, T. and Arai, T. (2009). A unified representation scheme for effective PSS development. CIRP Annals - Manufacturing Technology, 58, pp. 379-382.

9. Vargo, S.L., Lusch, R. F. (2008). Service-dominant logic: continuing the evolution. Journal of the Academy of Marketing Science, 36(1), pp. 1-10.

10. Mont, O. (2002). Clarifying the Concept of Product-Service System. Journal of Cleaner Production, 10 (3): 237-245.

11. Meier, H., Boßlau, M. (2013). Design for Engineering of Dynamic Business Models for Industrial Product-Service Systems. Springer. The Philosopher's Stone for Sustainability, pp. 179-184.

12. Hlupic, \& Robinson. (1998). Business Process Modelling and Analysis Using Discrete-Event Simulation. Winter Simulation Conference.

13. Shannon. (1998). Introduction to the Art and Science of Simulation. Winter simulation Conference.

14. Maisenbacher, S., Weidmann, D., Kasperek, D., Omer, M. (2014). Applicability of AgentBased Modeling for supporting Product-Service System development. Procedia CIRP, 16, pp. 356-361.

15. Duckwitz, S., Tackenberg, S. and Schlick, C. (2011). Simulation of human behavior in knowledge-intensive services. Institute of Industrial Engineering and Ergonomics, RWTH Aachen University, Germany.

16. Chesbrough, H. and Spohrer, J. (2006). A research manifesto for service science. Communications of the ACM, 49(7). 
17. Gronroos, C., Ojasalo, K. (2002). Service productivity: towards a conceptualization of the transformation of inputs into economic results in services. Journal of Business Research, 57(4), pp. 414-423.

18. Lee, S., Geum, Y., Lee, H., and Park, Y. (2012). Dynamic and multidimensional measurement of product-service system (PSS) sustainability: a triple bottom line (TBL)-based system dynamics approach. Journal of Cleaner Production, 32, pp. 173-182.

19. Lovrić, M., Li, T., and Vervest, P. (2013). Sustainable revenue management: A smart card enabled agent-based modelling approach. Decision Support Systems, 54, pp. 1587-1601.

20. Garetti, M., Rosa, P. and Terzi, S. 2012. Life Cycle simulation for the design of Product Service Systems. Computers in Industry, 63 (4), pp. 361-369.

21. Bianchi, N.P., Evans, S., Revetria, R., Tonelli, F. (2009). Influencing factors of successful transitions towards Product-Service Systems: a simulation approach. International Journal of mathematics and computers in simulation, 1(3), pp. 30-43.

22. Harpring, R., Evans, G. W., Barber, R., Deck, S. M. (2014). Improving efficiency in social services with discrete events simulation. Computers and industrial engineering, 70, pp. 159167.

23. Tateyama, T., Mikoshiba, S., Shimomura, Y. and Kawata, S. (2010). Service Flow Simulation using scene transition nets (STN) including satisfaction-attribute value functions. Proceeding of the ASME 2010 International Design Engineering Technical Conferences \& Computers and Information in Engineering Conference, August 15-18, 2010, Montreal, Canada.

24. Kim, S., Yoon, B. (2014). A systematic approach for new service concept generation: application of agent-based simulation. Expert Systems with Applications, 41, pp. 2793-2806.

25. Wang, B., Brême, S., Moon, Y.B. (2014). Hybrid modeling and simulation for complementing Lifecycle Assessment. Computers \& Industrial Engineering, 69, pp. 77-88.

26. McKenna, R., Reith, S., Cail, S., Kessler, A., Fichtner, W. (2013). Energy savings through direct secondary reuse: an exemplary analysis of the German automotive sector. Journal of Cleaner Production, 52, pp. 103-112.

27. Smith, V.M., Keoleian, G.A. (2004). The value of remanufactured engines. Life-cycle environmental and economic perspectives. Journal of Industrial Ecology, 8(1-2), pp. 193-221. 